\title{
The exploration and practice of integrated innovation teaching mode in the Applied Optics course
}

Dongmei Liu, Huifu Zhao, Xiuhua Fu, Jing Zhang

Dongmei Liu, Huifu Zhao, Xiuhua Fu, Jing Zhang, "The exploration and practice of integrated innovation teaching mode in the Applied Optics course," Proc. SPIE 10452, 14th Conference on Education and Training in Optics and Photonics: ETOP 2017, 104523X (16 August 2017); doi: 10.1117/12.2265233

EDEent: 14th Conference on Education and Training in Optics and Photonics, ETOP 2017, 2017, Hangzhou, China 


\title{
The exploration and practice of integrated innovation teaching mode in the "Applied Optics" course
}

\author{
( School of Opto-Electronic Engineering, Changchun University of Science and Technology,
}

Changchun, Jilin, china 130022)

\section{Dongmei Liu Huifu Zhao Xiuhua Fu Jing Zhang}

\begin{abstract}
In recent years, the Ministry of Education of China attaches great importance to the reform of higher education quality. As an important link in the reform of higher education, curriculum development is bound to promote the development of "quality-centered connotative education". Zhejiang University, Changchun University of Science and Technology, Southern Airlines University and other colleges and universities carried out a full range of close cooperation, proposed integrated innovation teaching mode of the course based on network technology. Based on this model, the course of "Applied Optics" has been practiced for two years. The results show that the integrated innovation teaching mode can fully realize the integration amplification effect among multiple colleges and universities and the depth sharing all types of resources. Based on the principle of co-building and sharing, mutual help, comprehensively improve the teaching quality of domestic related courses and promote the comprehensive development of the curriculum to meet the needs of learning society.
\end{abstract}

Key words: Network resources; Integration innovation Teaching mode; Applied optics

\section{Introductions}

"Centered on the talent training, motivated by reform and innovations, improve the overall quality of higher education" have become focus in the reformation and development of China's higher education in recent years, while the course construction is one of the most important and basic step in the comprehensive reform. With the rapid development of network technology, how to combine network resources, network technology and the curriculum construction together and improve the teaching quality is an important problem to be solved in higher education teaching.

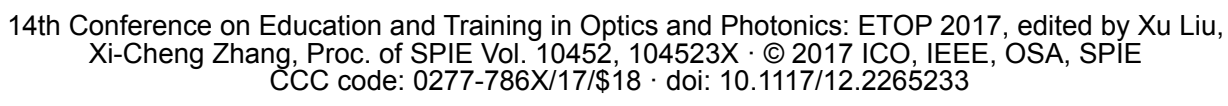


Since 2012, the ministry of education had carried out the sharing course of national high-quality resource, the selection and construction of open course. All kinds of high quality resources of he course had combined a certain degree of network resources and curriculum construction through the network information technology in the website " love courses ". However, as a sharing course of high-level and high-quality national excellent resources, there is still a series of problems such as the efficient utilization rate of shared resource is relatively low and not very practical, the hierarchical teaching is insufficient to the service students, lack of communication between teachers and students interaction. So its influence and the role of radiation demonstration are restricted to a certain degree.

\section{Integrated innovation teaching mode}

In order to fundamentally solve this problem, Zhejiang university, Changchun university of science and technology, Southern airlines university and other colleges and universities work closely in all directions. This paper proposes a new teaching mode based on network platform and network resources, namely the integrated innovation teaching mode.

The so-called "integrated innovation teaching mode" refers to the combination of integrated innovation concept into the curriculum construction. The institutions of different levels, different regions and different objects act as the main body of the integrated innovation, opening the network curriculum resources overall, at the same time constructing, optimizing and utilizing all kinds of network course resources through systematic, close and effective cooperation between colleges and universities subjects.

The use of flexible and diverse resources to the build way (The main body of colleges and universities independent or joint construct curriculum resources) to optimize the curriculum resources to achieve high quality courses or course groups and rapid construction, break teaching barriers, promote teachers resources and hard (soft) curriculum a real sharing. Improve the quality of the curriculum (course group) of the same kind (multi-area) by a limited number of high-quality curriculum resources. We promote the comprehensive reform of curriculum construction in colleges and universities through realizing the integrated amplification effect of curriculum 
teaching and forming integrated innovation teaching mode.

The "integrated innovation" is proposed, explored and constructed in order to explore a new teaching mode. We further improve the teaching quality and the present state of the national excellent resource sharing curriculum on the basis of the existing excellent course construction, fundamentally solve the problems of the current high-quality resources sharing curriculum. We inject power into the development of higher education by finding problems, puting forward ideas and solving problems.

\section{Exploration and practice of integrated innovation teaching mode of "Applied Optics"}

(1) Analyzes and summarizes the course of "Applied Optics" carefully, analyzes the advantages and disadvantages of the existing course teaching, and uses the network resources to analyze some existing similar resources sharing courses in China and find the common characteristics. And provides the theoretical basis for the new reform plan and measures, and provides the theoretical basis for the choice of colleges and universities to participate in the integrated innovation course.

(2) The choice of the main body of each university participating in integrated innovation. 3-4 domestic universities are selected to participate in the teaching practice of this project based on the characteristics of applied optics. The choice of integrated innovation should take into account the level of the overall teaching level of the course differences and the regional differences.

According to the characteristics of the domestic colleges "Applied Optics" and its related advantages, Zhejiang University, Nanchang University of Aeronautics and Changchun University of Science and Technology are selected as the main units of innovation. These schools have the characteristics of different levels of teaching, different levels of teaching objects, different teaching region and Synchronous teaching. It is in line with the basic criteria of subject choice, and has multiple representations.

We divide the school subject into two roles according to the division of tasks of each institution: The resource supplier and resources user in the course of specific teaching practice. Resource suppliers (Changchun University of Science and Technology, Zhejiang University) provide all relevant teaching resources and satisfy all the reasonable teaching requirements (including the flow of teachers) of the resource user object. The resource user object (Zhejiang University, Nanchang Aviation University, Changchun Polytechnic University) are free to use the resources provided by all resource providers without charge. 
(3) The teaching methods

All the main institutions are based on network technology and network platform "integrated innovation teaching mode." However, there are large differences in the selected main institutions regardless of the teacher situation, teaching level and student ability. In order to ensure the smooth progress of practice teaching, we have reached the following consensus, on the premise of integrated innovation teaching mode, we achieve the basic unity of teaching content in a certain framework. The main schools involved in the project standardize teaching syllabus, examination syllabus, examination methods, teaching courseware, textbook, etc. We can seek common ground and do not rigidly adhere to the form. Each user can be based on the actual situation of each unit to adopt a flexible and varied teaching method, self-design the course process, means not limited.

On the premise that the resource provider provides all the relevant resources of the course, the user should choose one of the three main teaching methods according to their own actual situation: one is the pure MOOCs teaching mode (all the teaching resources provided by the provider are used for curriculum teaching, the MOOCs are used for teaching assistance after-school). The other is the MOOCs auxiliary teaching method (traditional teaching methods are used in the classroom, the MOOCs teaching aids are used after class). Three is mixed teaching methods (the traditional teaching combine with the MOOCs teaching, some chapters using the traditional teaching methods, some chapters using MOOCs teaching methods, the MOOCs are used for teaching assistance after-school). In addition, some appropriate adjustments can be made based on the actual situation in the teaching process.

(4) Put forward the appropriate reform measures and programs and carry out the corresponding curriculum construction and practice of "Applied optics".

1) Selection of pilot experimental classes. A natural class is chose as pilot experimental class of "Applied Optics" integrated innovation teaching model in the integrated innovation of the main body of the school.

2) Achieve the basic unity of teaching content within a certain framework. The main schools involved in the project standardized teaching syllabus, exam outline, teaching courseware, text 
books etc.

3) Cross training, joint education. We can get rid of the institutional barriers between the institutions of higher education, optimize the allocation of teachers and achieve a certain degree of high-quality teachers' mobility without changing the existing educational personnel system.

The relevant teachers participating in the integration of innovative teaching model curriculum construction carry on the joint training to the experimental class students, carry out the "going out, please come in" teaching policy. The relevant teachers carry on the short-term course training, Q \& A, practical training and academic exchange for the students in the experimental class. Firstly, students can gain insight and broaden their horizons. Secondly, this can promote "different school same class" teachers communication, learn from each other, and common progress, and achieve win-win situation between teachers and students.

In the course of implementing the integrated innovation teaching model, in order to let the students feel the different teaching habits and teaching methods from the high level institutions, and experience the novel effects brought by the integrated innovation, we have formulated the " each teacher has the responsibility and obligation of intercollegiate communication, and effectively communicates the teaching ideas and teaching methods of the school curriculum during the inter-school teaching period. In this way, the students can experience the "real "teaching charm. The integrated innovation teaching model can achieve inter-school interaction between teachers and teachers and teacher-student interaction and carry out the teaching concept of cross training and joint education.

4) Strengthen interactive teaching. The teachers and students of main school construct a new teaching subject with "love course network" as the basic teaching platform, communicate with each other through the network of information technology, Q \& A, further strengthen the interaction between teachers and students, improve the teaching effect and realize the teaching effect optimization.

5) Proposition papers and assessment methods

The final exam adopts the combination proposition model of the school proposition, the 
supplier proposition and topic selection from the question bank. The type of examination is not limited, to achieve a certain degree of inter-school exam integration.

6) Carry out network teaching activities

The construction of network classroom is based on the ease of use and applicability. The "Applied Optics" network course provides a good learning and exchange platform. The platform not only has a wealth of professional resources information, but also user-friendly, open throughout the year, online resources to support free download for the course of the learner. The platform has a more powerful interaction between teachers and students, teachers and students to provide a free exchange of a broader space, in addition to the network platform provides an online test system, job submission system, virtual experimental system for the smooth development of network teaching.

7) The integration of high-quality resources to achieve network resource sharing. The main schools open to each other all the online resources, to achieve high quality resources to maximize efficiency and achieve deep level of resource sharing.

8) Optimize existing resources, strengthen the construction of resources. The main schools build new resources through the "single school alone construction and multi school construction" parallel way. Such as the joint construction of the "Applied Optics" test bank resources, the independent construction of the virtual experimental system (Changchun University of Science and Technology) and the independent construction of the online experimental system (Zhejiang University).

\section{The differences between inter-school cooperation and conventional inter-school} communication in the integrated innovation teaching mode

Because of the characteristics of "customer-oriented innovation", the diversification of innovation content, the diversification of innovation subject and its initiative, the advantages of "integrated innovation" not only lies in the simple superposition of all kinds of resources of each innovation subject, but also emphasis on the pursuit of resource optimization and its resulting integrated amplification effect. 
Conventional inter-school communication is: live meeting communication, short-term course training, teacher training, etc., most forms are larger than content, conversation is shallow, the effect is not ideal.

The integrated innovation teaching mode in the course of teaching should be reflected in: all-round use of inter-school resources, resource integration, resource optimization, resource amplification and achieve the deep sharing of all teaching resources. Integrated innovation teaching model hopes to break the institutional barrier and resource barrier between schools, construct a new teaching main body (group) by taking a certain course (course group, specialty) as a link in teaching. All the students (including college students and social learners) are learners (equivalent to students in the same school), teachers in all institutions are educators (equivalent to the same school teachers). This teaching model is dynamically updated; sustainability and resource amplification, the conventional inter-school exchange simply can't reach this close connection.

In the case of "Applied Optics" integration of innovative teaching model pilot class, inter-school cooperation is all-round. The teaching mode is not only the free use of curriculum resources, but also taking into account the whole process of classroom teaching. The whole process includes teaching early, middle and final exam, and even cover students' learning problems and employment issues one or two years later. Although this mode has only been carried out for two years, it has been involved in all aspects of curriculum teaching, even beyond the scope of conventional curriculum teaching. This kind of teaching mode is far beyond all previous inter school cooperation and communication both in scope and extent or depth, and truly realizes the "Applied Optics" course the communion between colleges and universities deeply, is a qualitative leap, obviously the amplification effect.

\section{Conclusions}

Over the past two years, several colleges and universities have carried on the exploration and the practice to the "Applied Optics" based on integrated innovation teaching mode. At present, the practice results of the "Applied Optics" course show that the integrated innovation teaching mode can further utilize the existing network resources and human resources, strengthen the effect of 
prestigious schools and professional brand effect based on the principles of co-building and co-sharing. And comprehensively enhance the quality of teaching in domestic courses, give full play to the integration effect between the multi-university subjects, realize the deep sharing of all kinds of resources, better services for different levels, different groups, different needs learners, promote the comprehensive development of the curriculum to meet the needs of a learning society.

In addition, the "integrated innovation teaching model" is not only applicable to the curriculum construction of a single course, but also applicable to the construction of professional courses group. If this model is effectively applied through the use of "point, line, surface" to gradually promote the exploration way, it will play a good promoting role in the comprehensive reform of curriculum construction in colleges and universities.

\section{References:}

[1] Liu Yandong's speech on the work conference of comprehensive improvement of Higher Education Quality.

[2] The declared relevant documents of 2012 years "national boutique resource sharing course". 